\title{
Differential expression of the Brunol/CELF family genes during Xenopus laevis early development
}

\author{
JINGYANG WU1,2,\#, CHAOCUI LI1,\#, SHUHUA ZHAO 1,2 and BINGYU MAO*,1 \\ ${ }^{1}$ CAS-Max Planck Junior Scientist Group, State Key Laboratory of Genetic Resources and Evolution, \\ Kunming Institute of Zoology, Chinese Academy of Sciences, Kunming, China and \\ ${ }^{2}$ Graduate University of Chinese Academy of Sciences, Beijing, China
}

\begin{abstract}
The BRUNOL/CELF family of RNA-binding proteins plays important roles in posttranscriptional regulation and has been implicated in several developmental processes. In this study, we describe the cloning and expression patterns of five Brunol genes in Xenopus laevis. Among them, only Brunol2 is maternally expressed and the zygotic expression of the other four Brunol genes starts at different developmental stages. During Xenopus development, Brunol1, 45 are exclusively expressed in the nervous system including domains in the brain, spinal cord, optic and otic vesicles. Brunol 2 and 3 are expressed in both the somatic mesoderm and the nervous system. Brunol2 is also extensively expressed in the lens. In transfected Hela cells, BRUNOL1, 2 and 3 proteins are localized in both the cytoplasm and the nucleus, while BRUNOL4 and 5 are only present in the cytoplasm, indicating their different functions.
\end{abstract}

KEY WORDS: Brunol, CELF, Xenopus, expression pattern

The BRUNOL (Bruno-like) family of RNA-binding proteins has been implicated in several post-transcriptional regulatory processes including pre-mRNA alternative splicing, mRNA stability and translation. The family was named due to their protein sequence similarity to Drosophila melanogaster Bruno (Good et al., 2000). The same family was also named CELF (UUG-BP1 and ETR-3 Like Factors) (Ladd et al., 2001). For the correspondence between these two systems please refer to Barreau et al. (2006) and Brimacombe and Ladd (2007). BRUNOL family proteins contain three RNA recognition motifs (RRMs), two in the $\mathrm{N}$ terminal region and one in the $\mathrm{C}$-terminal region. The $\mathrm{RRMs}$ show a high degree of sequence similarity but the sequences of the linker region between the second and third RRMs are less conserved (Barreau et al., 2006).

Mammalian BRUNOL family of proteins contains six members. A phylogenetic analysis suggests that the human BRUNOL proteins fall into two distinct subfamilies: one contains BRUNOL2, 3 (CUG-BP1 and ETR-3), and the other BRUNOL1, 4-6 (CELF3-6) (Ladd and Cooper, 2004). Brunol2 and 3 are broadly expressed in adult human and mice tissues, with strong expression in the heart, skeletal muscle, and brain (Good et al., 2000; Ladd et al., 2001; Ladd et al., 2004). In contrast, Brunol1, 4, 5 and 6 are mainly expressed in the brain (Good et al., 2000; Ladd et al., 2001; Ladd et al., 2004; Yang et al., 2007) with Brunol6 also in the kidney and testis (Ladd and Cooper, 2004). In chicken, 5 Brunol genes have been isolated, with Brunol1 (CELF3) missing. Among them, Brunol2 and 3 (CUG-BP1 and ETR-3) are broadly expressed in the early embryos, while Brunol4-6 (CELF4-6) are restricted primarily to the nervous system (Brimacombe and Ladd, 2007). In addition to Bruno, there are two more Brunolgenes in Drosophila, Bru-2 and 3, of which the expressions and functions are still unknown (Delaunay et al., 2004). There are two Brunol homologous genes in $C$. elegans, etr- 1 (homologous to Brunol2, 3) and unc-75 (homologous to Brunol1, 4-6). etr-1 is expressed in muscle cells (Milne and Hodgkin, 1999) while unc-75 in the nervous system (Loria et al., 2003). These data suggest that the two subfamilies of Brunolgenes arose very early in evolution and their expression patterns and possible functions are somehow conserved during evolution. Functional studies in $C$. elegans,

\footnotetext{
Abbreviations used in this paper:PBS, phosphate buffered saline; PCR, polymerase chain reaction; RRM, RNA recognition motif; WMISH, whole mount in situ hybridization.
}

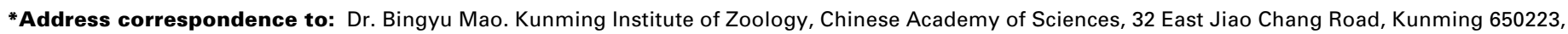
China. Tel: +86-871-5198-989. Fax: +86-871-519-3137. e-mail: mao@mail.kiz.ac.cn

\#Note: The indicated authors contributed equally to this work.
} 
Drosophila and mouse have revealed the involvement of BRUNOL proteins in the neural, muscle and germ cell development (Loria et al., 2003; Milne and Hodgkin, 1999; Timchenko et al., 2004; Kim-Ha et al., 1995; Kress et al., 2007; Dev et al., 2007).

In Xenopus, two members of Brunolgenes have been reported previously. Brunol1, also named etr-1, was found in a screen of genes expressed in noggin-induced neural tissue (Knecht et al., 1995). Xenopus BRUNOL2 (also known as EDEN-BP) was firstly isolated as a maternal factor mediating sequence-specific mRNA deadenylation in early Xenopus embryos (Paillard et al., 1998). Recently, more than 150 maternal mRNAs from Xenopus tropicalis egg extracts have been identified as potential BRUNOL2 targets (Graindorge et al., 2008), suggesting an important role of BRUNOL2 in early embryonic development. Xenopus Brunol2 is also implicated in the segmentation process. Inactivation of Brunol2causes severe segmentation defects, and the expression of segmentation markers in the Notch signalling pathway is disrupted (Gautier-Courteille et al., 2004).

In this study, we have cloned three new Brunolgenes (Brunol35) as well as different paralogs of Brunol1 and 2 of Xenopus laevis and systematically studied their expression patterns during early embryogenesis. The sub-cellular localization of the different BRUNOL proteins was also compared. The results suggest overlapping but different roles of the Brunol genes in Xenopus development.

\section{Results and Discussion}

\section{Isolation and phylogenetic analysis of Xenopus Brunol genes}

The Xenopus laevis Brunol1a (etr-1) and Brunol2a (EDEN-BP) have been reported previously (Knecht et al., 1995; Paillard et al., 1998). Since $X$. laevis is pseudotetraploid, there often exit two closely related paralogs for each gene (Hellsten et al., 2007). In our attempt to clone the $X$. laevis Brunol genes, we have found different paralogs for both Brunol1 and 2, designated Brunol1b and $2 b$, showing $98 \%$ and $92 \%$ identity with Brunol1a and $2 a$ respectively. Two Bruno/3 paralogs, designated Brunol3a and 3b, were isolated, with $88 \%$ sequence identity. Compared with BRUNOL3a, BRUNOL3b missed about 44 amino acids in the linker region, likely due to alternative splicing. X. laevis Brunol4 and 5 were cloned by PCR. One additional isoform of Brunol5

Fig. 1. Phylogenetic analysis of Xenopus BRUNOL proteins. (A) The representative structure of Xenopus BRUNOL proteins. (B) Sequence identities of the $\mathrm{X}$. laevis BRUNOL proteins. For BRUNOL proteins that have paralogs, the average values of the paralogs were shown. (C) Phylogenetic analysis of BRUNOL family proteins. ClustalW alignment, Poisson correction model, and Bootstrap test were used for the neighbor-joining (NJ) tree construction. The sequences of X. laevis BRUNOL3b, 4, 5, 5a have been deposited in GenBank under accession numbers EU743743-EU743746. Other accession nos. were as follows: Xenopus laevis (XI) BBRUNOL1a AAA81375, BRUNOL 1b AAH46942, BRUNOL2a AAH70706, BRUNOL2b NP_001084196, BRUNOL3a AAB09041; Xenopus tropicalis $(\mathrm{Xt})$ BBRUNOL1 BC154063, BRUNOL2 NP_001017152, BRUNOL3NP_001096417, BRUNOL4AAI21491, BRUNOL5AAI25740; Drosophila melanogaster (Dm) Bruno NP_723738, BRU-2 NP_788039, BRU-3 NP_729923. The BRUNOL protein sequences of human (Homo sapiens, $\mathrm{Hs}$ ), chicken (Gallus gallus, $\mathrm{Gg}$ ) and Caonorhabditis elegans (Ce) were used as in Brimacome and Ladd (2007).

(Brunol5a) was also isolated which missed one 49 base-pair exon to produce a premature stop codon, resulting in a truncated protein of only 132 amino acids. We failed to clone the Xenopus Brunol6 using primers according to conserved sequence among vertebrate Brunol6 mRNAs. Using mouse Brunol mRNA sequence queries, we could find only 5 chromosome loci in $X$. tropicalis genome. No ESTs of potential Brunol6 could be found either in $X$. laevis or tropicalis. The predicted partial sequence listed as $X$. tropicalis BRUNOL6 (CELF6) in Brimacombe and Ladd (2007) was proved to be the C-terminal part of BRUNOL1. It is possible that Brunol6 is missing in Xenopus. In chick, Brunol1 (CELF3) is missing due to a deletion event. The Xenopus BRUNOL proteins all contained three conserved RRMs with a linker region between the second and third one (Fig. 1A). Among the 5 Xenopus BRUNOL proteins, BRUNOL2 and BRUNOL3 proteins are more closely related with an overall sequence identity of $72 \%$. BRUNOL1, 4 and 5 form another sub-group and the average sequence identity among them was about $66 \%$. The overall sequence identity between the two sub-groups was below $45 \%$ (Fig. 1B).

Using MEGA program (Kumar et al., 2004), we studied the phylogenetic relationship of the BRUNOL proteins in human,

A

B

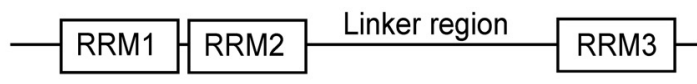

\begin{tabular}{|c|c|c|c|c|c|}
\hline BRUNOL & 1 & 2 & 3 & 4 & 5 \\
\hline 1 & 100 & 41 & 44 & 71 & 64 \\
\hline 2 & & 100 & 72 & 42 & 43 \\
\hline 3 & & & 100 & 44 & 45 \\
\hline 4 & & & & 100 & 67 \\
\hline 5 & & & & & 100 \\
\hline
\end{tabular}

C

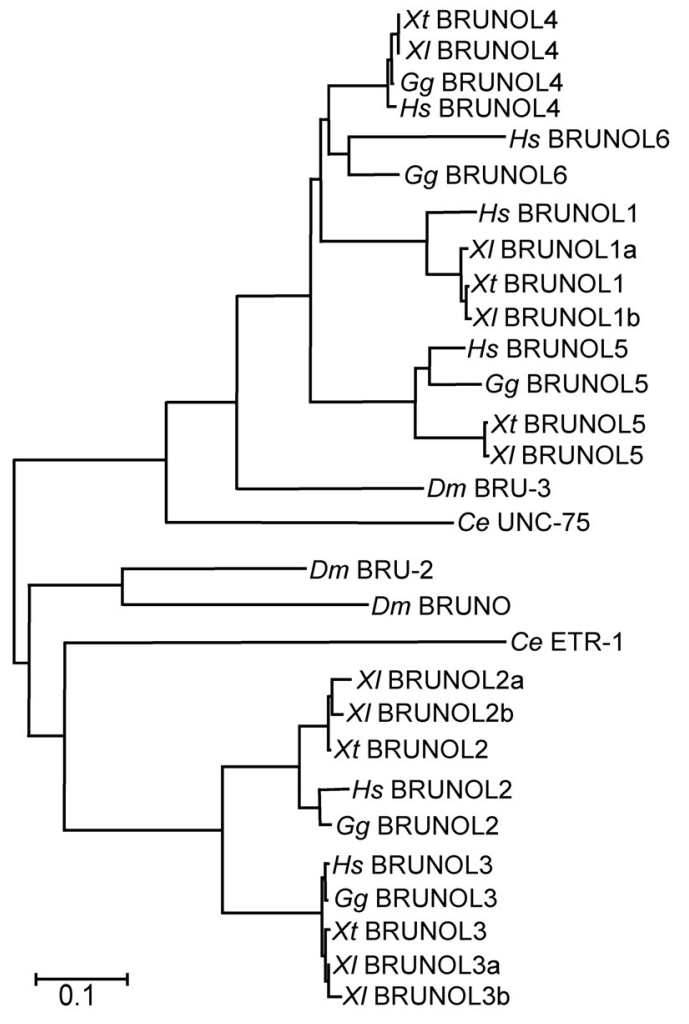


chick, $X$. laevis and tropicalis, Drosophila and C. elegans (Fig. 1C). The BRUNOL proteins fell into two sub-groups based on their overall sequence similarity, one contained BRUNOL2 and 3, the other contained BRUNOL1 and 4-6. The Drosophila and C. elegans BRUNO proteins also fitted into the two BRUNOL subfamilies, suggesting an early diversification of the two subfamilies during evolution.

\section{Temporal expression of Xenopus Brunol genes}

To investigate the temporal expression patterns of the Brunol genes in $X$. laevis, a series of RT-PCR analysis was carried out (Fig. 2A). Brunol2a and $b$ were detected strongly maternally as reported previously (Gautier-Courteille et al., 2004). Their expression was weak at the beginning of the neurula stage and became stronger at later stages. All the other Brunol genes were not maternally expressed and their expression started at different developmental stages. Brunol1 began to express at about stage 11 and increased with development. From stage 19 on, it kept strongly expressed. The transcripts of Brunol3a and $b$ could be detected weakly at stage 19 and kept expressed at later stages. Brunol4 and 5 started to express at stage 30 and 25 respectively and were both strongly expressed at later stages.

Different paralogs of the same Brunolgenes showed the same temporal expression patterns during development, although their expression levels were slightly different. Since the sequences of Brunol1 $a$ and $b$ were $98 \%$ identical, it was difficult to design PCR primers to distinguish them. They differed in one fragment in which Brunol1b contained two additional Ncol restriction sites. This fragment was amplified by PCR and after Ncol digestion, it was able to distinguish the two paralogs. At stages 11 to 30 , the expression level of Brunol1a was stronger than Brunol $1 b$ with a ratio of about 2.5:1. At stages 36 and 43, the two paralogs were expressed at similar levels (Fig. 2B).

\section{Spatial expression of Brunol genes during Xenopus laveis early embryogenesis}

To avoid cross reaction, the sequences corresponding to the less conserved linker regions between RRM2 and 3 were chosen for probes preparation. For the different paralogs of the same gene, it was unable to distinguish the expression patterns of individual paralogs using these probes due to their high sequence similarities.

The temporal expression patterns of the Brunol genes from the WMISH results fitted well with the RT-PCR analysis. Brunol2 was the only one maternally expressed and no expression was detected for Brunol1, 3, 4 and 5 till the end of gastrulation.

As reported previously, Brunol1 was specifically expressed in the neural tissue and stronger in the anterior region (Fig. 3A, Knecht et al., 1995). At stage 13 and 14, weak expression of Brunol1 was detected in the anterior neural plate region as well as two patches lateral to the brain region, representing the presumptive trigeminal placodes (Fig. 3Aa-d). From stage 16 to 25, Brunol1 was more abundantly expressed in the whole neural tube but weak in the roof plate and floor plate regions (Fig. 3Ae-k). At stage 30, Brunol1 was strongly expressed in the forebrain, midbrain, hindbrain, the epiphysis, spinal cord and optic vesicles, but not at mid-hindbrain boundary (Fig. 3Al). At stage 36, its expression remained strong in the above regions and appeared also in the otic vesicles (Fig. 3Am-p). In the eyes, it was strongly ex- pressed in the retinas (Fig. $3 \mathrm{Ao}$ ).

Maternal Brunol2mRNA has been reported to distribute homogeneously in the early Xenopus embryos (Gautier-Courteille et al., 2004) and vegetally in zebrafish (Suzuki et al., 2000). In our study, however, Brunol2 transcripts were detected at the animal poles in the unfertilized eggs and cleavage and blastula stage embryos (Fig. 3Ba and data not shown). During gastrulation, it was expressed in the ectoderm but not in the yolk plug region (Fig. $3 \mathrm{Bb})$. At stage 13, it was broadly expressed in the whole embryo (Fig. 3Bc). At stages 14 and 16, its expression became confined in the para-axial mesoderm and the neural plate (Fig. 3Bd-g). At stages 19 and 26, it was expressed in the somites and neural tube (Fig. 3Bh-m). At stage 19, it was also detected in the trigeminal placodes and the presumptive eye fields (Fig. 3Bi). At tailbud stages, Brunol2 was expressed in the brain, spinal cord, optic and otic vesicles and the branchial arches (Fig. 3Bn-s). It was extensively expressed in the lens (Fig. 3Bq), which was also the case for zebrafish Brunol2 (Suzuki et al., 2000), suggesting a conserved role for BRUNOL2 in lens development. Brunol2 remained weakly expressed in the somites in the trunk region and strongly in the tail region (Fig. 3Bo,p,s).

Brunol3 began to be expressed at about stage 15 in the paraaxial mesoderm (data not shown). Its expression became clear in the somitic mesoderm (Fig. 3Ca,b) at stage 18 and remained strong in the somites through stages 25 to 30 (Fig. 3Cc,d,e). At stage 25, Brunol3 began to express also weakly in the head region (Fig. 3Cc). In the nervous system, Brunol3 was detected in patches in the midbrain, hindbrain, anterior spinal cord and optic vesicles at stage 30 , but was absent at the midbrain-hindbrain boundary (Fig. 3Ce). At stage 36, the expression of Bruno/3 in the somites became very weak and clear only in the tail region (Fig. $3 \mathrm{Cf}, \mathrm{g}, \mathrm{j})$. In the nervous system, its expression remained strong in patches in the brain region and also in the optic and otic vesicles

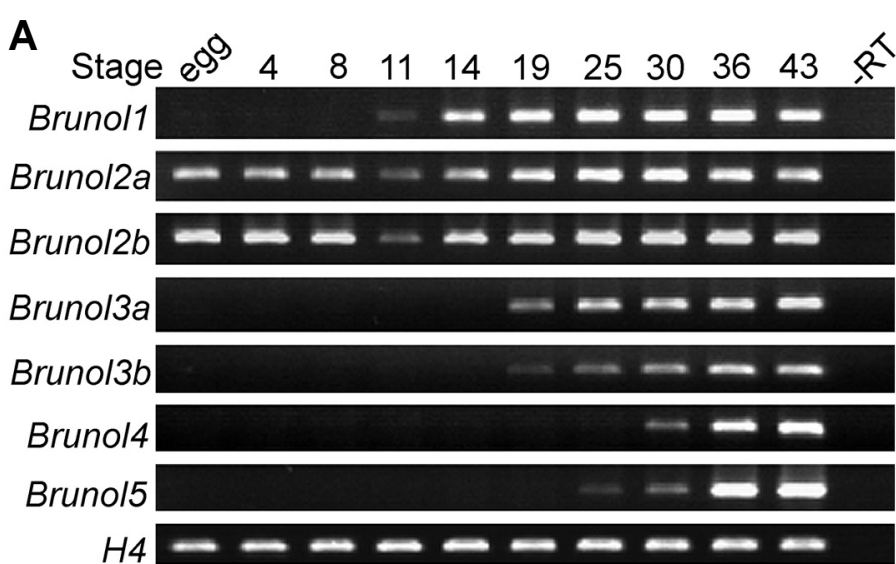

B

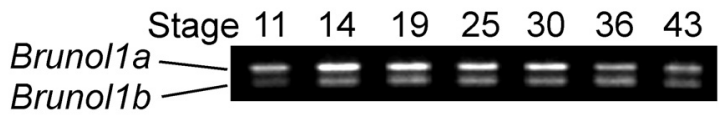

Fig. 2. Temporal expression of Xenopus Brunol genes. (A) $R T-P C R$ analysis of the developmental expression of the Xenopus Brunol genes. egg: unfertilized egg. Histone 4 (H4) was used as a loading control. (B) The Brunol1 PCR products after Ncol digestion, showing the differential expression levels of Brunol1a and $1 \mathrm{~b}$. 

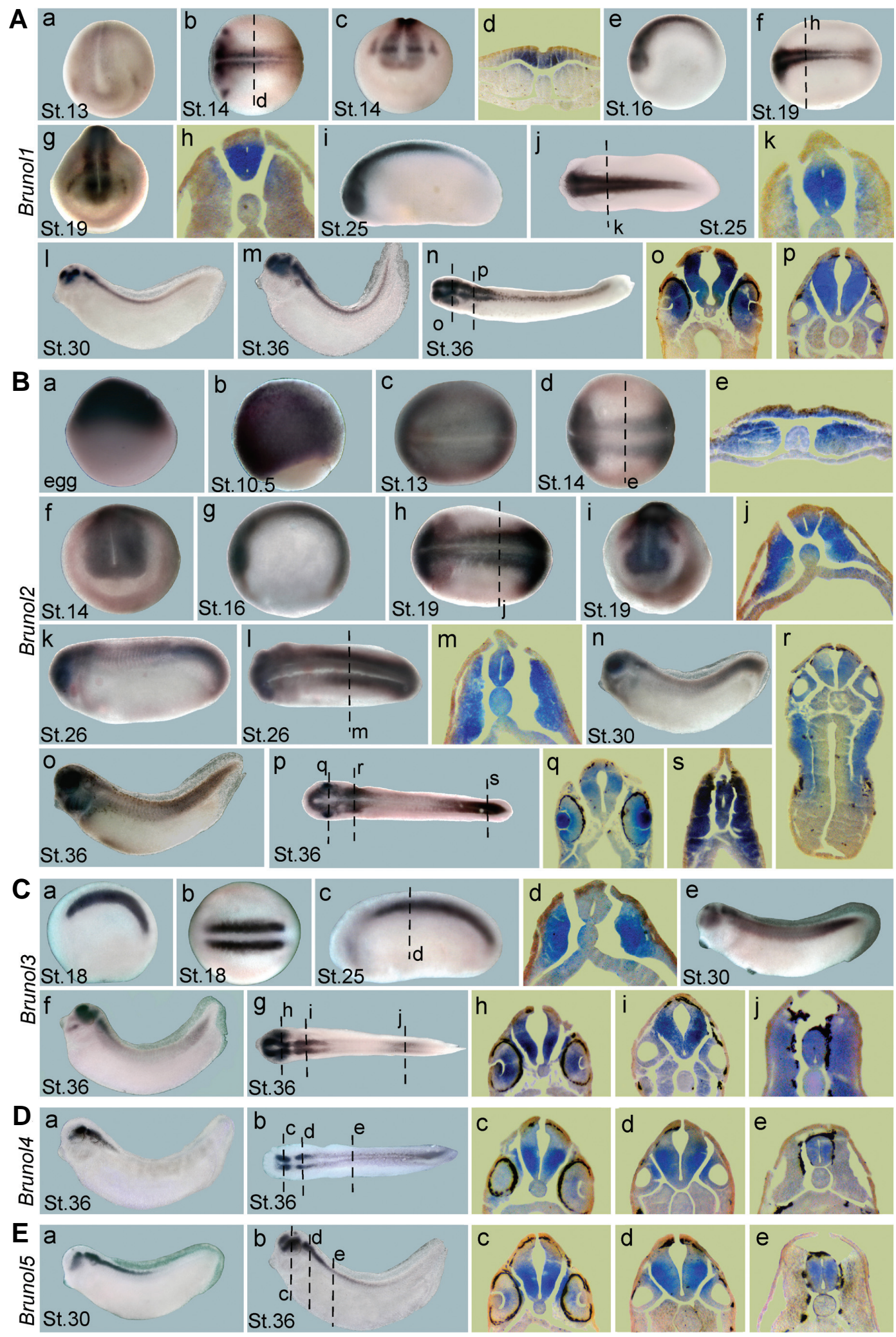

Fig. 3. Embryonic expression of the $\boldsymbol{X}$. laevis Brunol genes at the indicated stages. (A) Brunol1, $(a, c, g)$, frontal views, dorsal to the top; $(b, f, j, n)$, dorsal views, anterior to the left; $(e, i, l, m)$, lateral views, anterior to the left. (B) Brunol2, (a,b), lateral views, animal pole to the top; (c, d, $h, l, p)$, dorsal views, anterior to the left; $(f, i)$, frontal views, dorsal to the top; $(g, k, n, o)$, lateral views, anterior to the left. (C) Brunol3, (a,c,e,f), lateral views, anterior to the left; (b,g), dorsal views, anterior to the left. (D) Brunol4, (a), lateral view, anterior to the left; (b), dorsal view, anterior to the left. (E) Brunol5, $(a, b)$, lateral view, anterior to the left. The positions of the sections were indicated. 


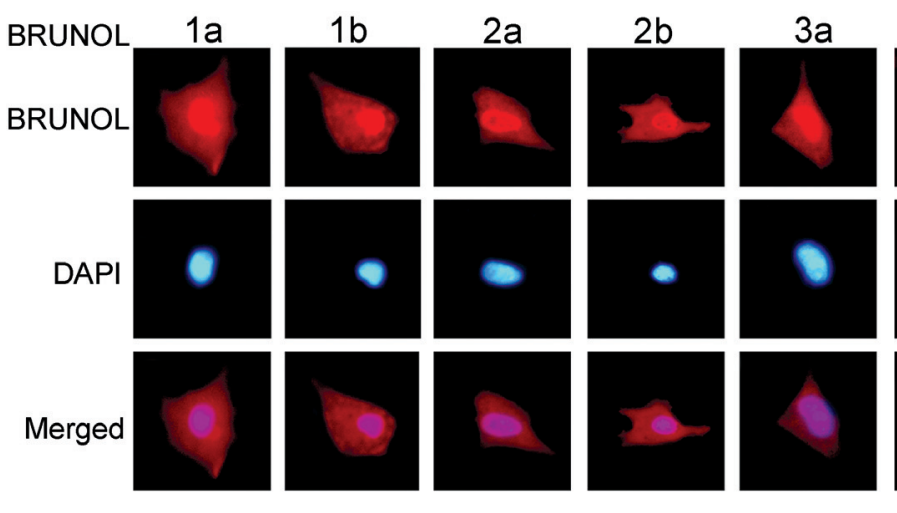

(Fig. 3Cg,h,i). At stage 36, it was also detected in the facial epibranchial placode (Fig. 3Cf).

The expression of Bruno4 and 5 were both restricted in the nervous system. Brunol5 began to express at about stage 25 while Brunol4 started at stage 30 . At stage 30 , Brunol5 was detected in the ventral part of the brain and anterior half of the spinal cord as well as the optic and otic vesicles (Fig. 3Ea). At stage 36, Brunol4 and Brunol5 showed overlapping expressing domains in the ventral midbrain, hindbrain, anterior spinal cord, optic and otic vesicles (Fig. 3 D,E). Brunol5 but not Brunol4 was detected in the dorsal forebrain and epiphysis (Fig. $3 \mathrm{D}, \mathrm{E}$ ).

Post-transcriptional regulation exerted by RNA-binding proteins plays important roles in the development and maintenance of the nervous system (reviewed in Perrone-Bizzozero and Bolognani, 2002). For example, the BRUNOL related ELAV/Hu family proteins are also differentially expressed during neurogenesis and are essential for proper neural development (Perron et al., 1999; Perrone-Bizzozero and Bolognani, 2002). Our data showed that the Xenopus Brunolgenes were all strongly expressed in the nervous system, adding more complexity to the post-transcriptional control of neural development. The five Brunol genes were all expressed in the neural retinas in the developing eye, with Brunol2 also strongly in the lens, suggesting an important role of BRUNOLs in eye development.

\section{Subcellular localization of BRUNOL proteins}

The full length Brunol open reading frames (ORF) were fused with a C-terminal Flag tag coding sequence and the subcellular localization of the BRUNOL proteins was detected using anti-Flag antibody in transfected Hela cells. BRUNOL1a, 1b, 2a, $2 \mathrm{~b}$ and $3 a$ were all localized in both the cytoplasm and the nucleus, while BRUNOL3b, 4 and 5 distributed only in the cytoplasm (Fig. 4). Interestingly, BRUNOL3a and $3 b$ showed different localization. In the nucleus, BRUNOLs have been shown to regulate the alternative splicing of some pre-mRNAs through binding to a U/G rich sequence element (Barreau et al., 2006). In the cytoplasm, the BRUNOL proteins control the translation or stability of target mRNAs through binding to sequence elements in the 5'- or the 3'regions (lakova et al., 2004; Timchenko et al., 1999). The different subcellular localization of the BRUNOL proteins might indicate their different functions.

\section{Materials and Methods}

Cloning of Xenopus laevis Brunol genes and phylogenetic analysis Through database searches using mouse Brunol mRNA sequences

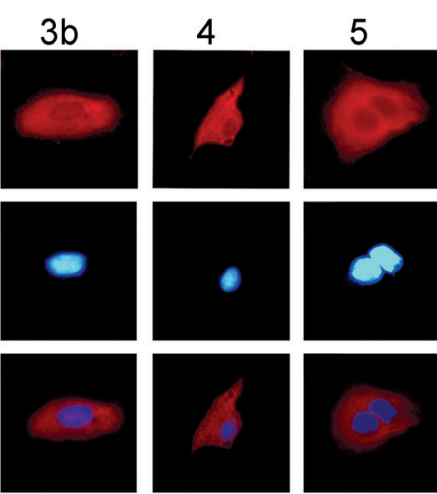

Fig. 4. Subcellular localization of the indicated Xenopus BRUNOL proteins. BRUNOL proteins were detected using anti-FLAG antibody. The cells were also stained with DAPI to visualize the nuclei.

as queries, unigene clusters were identified for $X$. laevis Brunol1a (XI.986), 1b (XI.12160), 2a (XI.12254), 2b (XI.25921) and 3 (XI.1068). PCR primers were designed according to the EST sequences to amplify the full open reading frames. For $X$. laevis Brunol4 and 5, primers were designed according to the corresponding $X$. tropicalis EST sequences. The primers used were:

Brunol1: forward 5'- TGTTGGGTGGTGGGAGTCTGTTCCTT -3' and reverse 5'- ATGTTCTCCTTGGTCCAGCAGCAGT -3',

Brunol2a: forward 5'- CTGATCAAGAAAACGCTAATGGGGGATA-3' and reverse 5'- ATGGACAAATGGCAGGAAGGGATCAG -3',

Brunol2b: forward 5'- ATAATGAATGGCACAATGGACCACCC -3' and reverse 5'- ATGGACAAATGGCAGGAAGGGATCAG -3',

Bruno/3: forward 5'- GCTTCTGTGGCATTGATGTTTGAGC -3' and reverse 5'- CTGGGGTTAGGATCAGTAAGGTTTGC -3',

Brunol4: forward 5'- CAGAGAGACCAGGCAGCTTCCTCT TG -3' and reverse 5'-TCAGTAAGGGCGGTTGGCATCCTTCG -3',

Brunol5: forward 5'- ATGGCCAGACTGACGGAGAGA GAG -3' and reverse 5'- TCAGTATGGTTGGGTTGTGTCCTTAGGC-3'.

cDNAs were reverse transcribed using total RNA from stage 13 to 36 as template and oligo-T 18 as primer (ThermpScript RT-PCR System, Invitrogen). The PCR products were then cloned into PGEM-T vectors (Promega) and the inserts were full length sequenced.

Phylogenetic tree construction was performed as described (Zhao et al., 2007).

\section{$R T-P C R$ assay and restriction enzyme digestion}

Total RNAs were extracted using TRIzol regent (Invitrogen) from $X$. laevis embryos at different stages, and the first strand cDNAs were synthesized using random hexamer nucleotide as RT primers (RevertAid $\mathrm{H}$ minus first strand cDNA Synthesis kit, Fermentas). The amount of the templates was adjusted according to Histone $4(\mathrm{H} 4)$ expression levels. PCR assays were carried out in the linear phase.

Primers used were:

Brunol1: forward 5'- CGCACAMAGCGCTTACCTCAAT -3' and reverse 5'- GTGGCAGTGAGTGTTGGTGGAG -3',

Brunol2a: forward 5'- TGGGGTAACCTAGCTGGACTCG -3'and reverse 5'- GGGGACTGCTGGAAGAAGTGAG -3',

Brunol2b: forward 5'- TGGGGTAACCTGACTGGACTGA -3' and reverse 5'- GGGGGCTGCTGGAAGAAGTGAG -3',

Brunol3a: forward 5'- GACCATGGAGGGCTGTTCTTCA -3' and reverse 5'- ACCCAGGTTACTGGGGGTGGTA -3',

Brunol3b: forward 5'- GACCATGGAGGGCTGTTCTTCA -3' and reverse 5'- ATGCACCCAGGTTACKGGAGGA -3',

Brunol4: forward 5'- CCAGCTGTGCCTAGCATTCCAT -3' and reverse 5'- GGCTGTGGAAAGGCTTGACTGA -3',

Brunol5: forward 5'- AGACTATGCCTGGGGCCTCATC -3' and reverse 5'- GTAGCTCCCATGCGAAGTGGAC -3'.

PCR conditions: $94^{\circ} \mathrm{C}$ for $2 \mathrm{~min} ; 30$ cycles of $94^{\circ} \mathrm{C}$ for $30 \mathrm{sec}, 55^{\circ} \mathrm{C}$ for $30 \mathrm{sec}, 72^{\circ} \mathrm{C}$ for $30 \mathrm{sec}$; followed by one cycle of $72^{\circ} \mathrm{C}$ for $5 \mathrm{~min}$.

To distinguish Brunol1 $a$ and $b$, the Brunol1 PCR products were 
digested with Ncol before agarose gel electrophoresis, and the software Quantity One (Bio-Rad) was used to analyze the bands' density.

\section{Embryos, in situ hybridization and section}

In vitro fertilization, embryo culture, and whole mount in situ hybridization (WMISH) of Xenopus embryos were carried out as described (Zhao et al., 2007). Stained embryos of selected stages were embedded in paraffin, sectioned at $30 \mu \mathrm{m}$, and photographed using a light microscope (Leica).

\section{Cell transfection and immunohistochemistry}

The ORFs of Brunol genes were cloned in frame into a eukaryotic expression vector pCS2+ with a Flag tag coding sequence. Cultured Hela cells were then transfected with these vectors using Lipofectamine2000 (Invitrogen) in 96-well plates. At $24 \mathrm{~h}$ after transfection, cells were fixed with $3.7 \%$ formaldehyde for $20 \mathrm{~min}$, permeablized in $0.1 \%$ Triton X-100/ PBS for $10 \mathrm{~min}$, washed with PBS, blocked in $1 \%$ BSA/PBS for $1 \mathrm{~h}$, and then treated with mouse anti-FLAG antibody (Sigma) for $1.5 \mathrm{~h}$. After washing with $1 \%$ BSA/PBS for 5 times, cells were treated with Cy3conjugated anti-mouse secondary antibody (Sigma) for $1.5 \mathrm{~h}$. The cells were washed and stained with $1 \mu \mathrm{g} / \mathrm{ml}$ DAPI (Sigma) for $5 \mathrm{~min}$ and then visualized using a fluorescence microscope (Leica).

\section{Acknowledgements}

This work was supported by grants from the National Natural Science Foundation of China (30425011 and 305303800), the Key State Research Program from the Ministry of Science and Technology of China (2006CB943902 and 2007CB947201) and the Innovation Project of Chinese Academy of Sciences (KSCX2-YW-R-090).

\section{References}

BARREAU, C., PAILLARD, L., MEREAU, A. and OSBORNE, H. B. (2006). Mammalian CELF/Bruno-like RNA-binding proteins: molecular characteristics and biological functions. Biochimie 88: 515-525.

BRIMACOMBE, K. R. and LADD, A. N. (2007). Cloning and embryonic expression patterns of the chicken CELF family. Dev Dyn 236: 2216-2224.

DELAUNAY J., LE MEE G., EZZEDDINE N., LABESSE G., TERZIAN C., CAPRI M. AND AIT-AHMED O. (2004). The Drosophila Bruno paralogue Bru-3 specifically binds the EDEN translational repression element. Nucleic Acids Res 32: 30703082

DEV, A., NAYERNIA, K., MEINS, M., ADHAM, I., LACONE, F. and ENGEL, W. (2007). Mice deficient for RNA-binding protein brunol1 show reduction of spermatogenesis but are fertile. Mol Reprod Dev 74: 1456-1464.

GAUtier-COURTEILle, C., Le ClAinCHE, C., BARREAU, C., AUDIC, Y., GRAINDORGE, A., MANIEY, D., OSBORNE, H. B. and PAILLARD, L. (2004). EDEN-BP-dependent post-transcriptional regulation of gene expression in Xenopus somitic segmentation. Development 131: 6107-6117.

GOOD, P. J., CHEN, Q., WARNER, S. J. and HERRING, D. C. (2000). A family of human RNA-binding proteins related to the Drosophila Bruno translational regulator. J Biol Chem 275: 28583-28592.

GRAINDORGE, A., LE TONQUEZE, O., THURET, R., POLLET, N., OSBORNE, H. B. and AUDIC, Y. (2008). Identification of CUG-BP1/EDEN-BP target mRNAs in Xenopus tropicalis. Nucleic Acids Res 36: 1861-1870.

HELLSTEN, U., KHOKHA M.K., GRAMMER, T.C., HARLAND, R.M., RICHARDSON, P. and ROKHSAR, D.S. (2007). Accelerated gene evolution and subfunctionalization in the pseudotetraploid frog Xenopus laevis. BMC Biol. 5:31.
IAKOVA, P., WANG, G. L., TIMCHENKO, L., MICHALAK, M., PEREIRA-SMITH, O. M., SMITH, J. R. and TIMCHENKO, N. A. (2004). Competition of CUGBP1 and calreticulin for the regulation of $\mathrm{p} 21$ translation determines cell fate. EMBO J23: 406-417.

KIM-HA, J., KERR, K. and MACDONALD, P. M. (1995). Translational regulation of oskar mRNA by bruno, an ovarian RNA-binding protein, is essential. Cell 81: 403-412.

KNECHT, A. K., GOOD, P. J., DAWID, I. B. and HARLAND, R. M. (1995). Dorsalventral patterning and differentiation of noggin-induced neural tissue in the absence of mesoderm. Development 121: 1927-1935.

KRESS, C., GAUTIER-COURTEILLE, C., OSBORNE, H. B., BABINET, C. and PAILLARD, L. (2007). Inactivation of CUG-BP1/CELF1 causes growth, viability, and spermatogenesis defects in mice. Mol Cell Biol 27: 1146-1157.

KUMAR, S., TAMURA, K. and NEI, M. (2004). MEGA3: Integrated software for Molecular Evolutionary Genetics Analysis and sequence alignment. Brief Bioinform 5: 150-163.

LADD, A. N., CHARLET, N. and COOPER, T. A. (2001). The CELF family of RNA binding proteins is implicated in cell-specific and developmentally regulated alternative splicing. Mol Cell Biol 21: 1285-1296.

LADD, A. N. and COOPER, T. A. (2004). Multiple domains control the subcellular localization and activity of ETR-3, a regulator of nuclear and cytoplasmic RNA processing events. J Cell Sci 117: 3519-3529.

LADD, A. N., NGUYEN, N. H., MALHOTRA, K. and COOPER, T. A. (2004). CELF6, a member of the CELF family of RNA-binding proteins, regulates musclespecific splicing enhancer-dependent alternative splicing. J Biol Chem 279 17756-17764.

LORIA, P. M., DUKE, A., RAND, J. B. and HOBERT, O. (2003). Two neuronal, nuclear-localized RNA binding proteins involved in synaptic transmission. Curr Biol 13: 1317-1323.

MILNE, C. A. and HODGKIN, J. (1999). ETR-1, a homologue of a protein linked to myotonic dystrophy, is essential for muscle development in Caenorhabditis elegans. Curr Biol 9: 1243-1246.

PAILLARD, L., OMILLI, F., LEGAGNEUX, V., BASSEZ, T., MANIEY, D. and OSBORNE, H. B. (1998). EDEN and EDEN-BP, a cis element and an associated factor that mediate sequence-specific mRNA deadenylation in Xenopus embryos. EMBO J 17: 278-287.

PERRON, M., FURRER, M.P., WEGNEZ, M. and THODORE, L. (1999). Xenopus elav-like genes are differentially expressed during neurogenesis. Mech Dev84 139-142.

PERRONE-BIZZOZERO, N. and BOLOGNANI, F. (2002). Role of HuD and other RNA-binding proteins in neural development and plasticity. J Neurosci Res 68 : 121-126

SUZUKI, H., MAEGAWA, S., NISHIBU, T., SUGIYAMA, T., YASUDA, K. and INOUE, K. (2000). Vegetal localization of the maternal mRNA encoding an EDEN-BP/Bruno-like protein in zebrafish. Mech Dev 93: 205-209.

TIMCHENKO, N. A., PATEL, R., IAKOVA, P., CAI, Z. J., QUAN, L. and TIMCHENKO, L. T. (2004). Overexpression of CUG triplet repeat-binding protein, CUGBP1, in mice inhibits myogenesis. The J Biol Chem 279: 13129-13139.

TIMCHENKO, N. A., WELM, A. L., LU, X. and TIMCHENKO, L. T. (1999). CUG repeat binding protein (CUGBP1) interacts with the $5^{\prime}$ region of $\mathrm{C} / \mathrm{EBPbeta}$ mRNA and regulates translation of C/EBPbeta isoforms. Nucleic Acids Res 27 4517-4525.

YANG, Y., MAHAFFEY, C. L., BERUBE, N., MADDATU, T. P., COX, G. A. and FRANKEL, W. N. (2007). Complex seizure disorder caused by Brunol4 deficiency in mice. PLoS Genet 3: e124.

ZHAO, S., JIANG, H., WANG, W. and MAO, B. (2007). Cloning and developmental expression of the Xenopus Nkx6 genes. Dev Genes Evol 217: 477-483. 


\section{Further Related Reading, published previously in the Int. J. Dev. Biol.}

See our recent Special Issue Fertilization, in honor of David L. Garbers and edited by Paul M. Wassarman and Victor D. Vacquier at: http://www.ijdb.ehu.es/web/contents.php?vol=52\&issue=5-6

Differential expression of two TEF-1 (TEAD) genes during Xenopus laevis development and in response to inducing factors François Naye, Karine Tréguer, Fabienne Soulet, Corinne Faucheux, Sandrine Fédou, Nadine Thézé and Pierre Thiébaud Int. J. Dev. Biol. (2007) 51: 745-752

Identification of a second Xenopus twisted gastrulation gene

Michael Oelgeschläger, Uyen Tran, Kristina Grubisic and Edward M De Robertis Int. J. Dev. Biol. (2004) 48: 57-61

Heterogeneous nuclear ribonucleoprotein complexes from Xenopus laevis oocytes and somatic cells

A Marcu, B Bassit, R Perez and S Piñol-Roma

Int. J. Dev. Biol. (2001) 45: 743-752

Misexpression of the RNA-binding protein ELRB in Xenopus presumptive neurectoderm induces proliferation arrest and programmed cell death

M Perron, M P Furrer, M Wegnez and L Théodore

Int. J. Dev. Biol. (1999) 43: 295-303

Zinc finger proteins in early Xenopus development

T Hollemann, E Bellefroid, R Stick and T Pieler

Int. J. Dev. Biol. (1996) 40: 291-295

Expression of GTP-binding protein gene drg during Xenopus laevis development S Kumar, M Iwao, T Yamagishi, M Noda and M Asashima Int. J. Dev. Biol. (1993) 37: 539-546
5 yr ISI Impact Factor $(2008)=3.271$

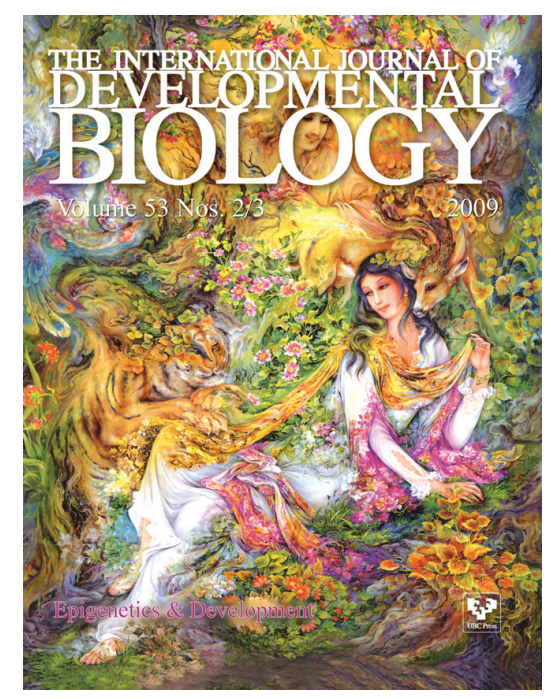

